TP Periodica Polytechnica Chemical Engineering

60(2), pp. 74-77, 2016

DOI: $10.3311 /$ PPch. 8261

Creative Commons Attribution (i)

RESEARCH ARTICLE

\section{Benefits of Jet Reactor Application in Alkaline Gas Purification}

\author{
Éva Molnár ${ }^{1 *}$, Dóra Rippel-Pethő ${ }^{1}$, Géza Horváth ${ }^{1}$, \\ Zoltán Hodai ${ }^{1}$, Róbert Bocsi ${ }^{1}$, Janka Bobek ${ }^{1}$
}

Received 20 May 2015; accepted after revision 29 November 2015

\begin{abstract}
Our energy requirements have increased enormously in the last decades. We can get a significant amount of energy by the combustion of flammable gas mixtures of hydrocarbons. Proper gas purification prior to use is essential. A hydrocarbon-based gas mixture which contains sulfur compounds is called sour gas. $\mathrm{H}_{2} \mathrm{~S}$ is one of the most problematic compounds in the transportation and utilization of natural gas or biogas. $\mathrm{H}_{2} \mathrm{~S}$ is a toxic gas. It is corrosive in the presence of water. Upon the combustion of natural gas $\mathrm{H}_{2} \mathrm{~S}$ is converted into $\mathrm{SO}_{2}$ which is not only harmful for the environment by causing acid rain but also constitutes a danger to human health. There are several methods of reducing the content of $\mathrm{H}_{2} \mathrm{~S}$ in natural gas. However, the usability of these methods is limited due the increasingly strict environmental regulations. Our future aim is to develop a new, efficient and selective method. Selectivity is important to avoid unnecessary energy and chemicals consumption. Alkali-based competitive chemisorption method appears to be a good choice. $\mathrm{H}_{2} \mathrm{~S}$ reacts with $\mathrm{NaOH}$ faster than $\mathrm{CO}_{2}$, which is the basis of the selectivity. Residence time is a key parameter for the efficiency of the operation. The essence of the method is the very short contact time, thus intensive contact between the gas and liquid phases has to be ensured along with rapid phase separation. Using a spray technology such as in Jet reactor is feasible. The advantage of the application of a Jet reactor is that various parameters can be changed.
\end{abstract}

\section{Keywords}

hydrogen sulfide, carbon dioxide, competitive chemisorption, gas purification, Jet reactor

\section{Introduction}

The population of Earth and at the same time the demand for energy has increased in the last decades. These days it is one of the most important tasks to find a solution to meet this requirement. However, environmental and economic criteria also have to be taken into consideration. A significant amount of energy can be liberated by of the combustion of hydrocarbon gases. Natural gas is one of the purest fossil energy sources because it only generates $\mathrm{CO}_{2}$ and water. Of course this is only true if the gas does not contain contaminants such as $\mathrm{H}_{2} \mathrm{~S}$ or mercaptans. Hydrocarbon gases with sulfur content are called sour gases. $\mathrm{H}_{2} \mathrm{~S}$ gas is a compound associated with natural gas production capable of causing great damage. It is toxic gas and also corrosive for the pipelines in the presence of water. It is converted into $\mathrm{SO}_{2}$ upon the combustion of natural gas which is not only harmful for the environment by causing acid rain, but also constitutes a danger to human health [1].

There are several procedures to reduce the content of $\mathrm{H}_{2} \mathrm{~S}$ in natural gas. However the usability of these procedures is limited due the increasingly strict environmental regulations. One of the most widely used and effective method is fixed bed adsorption but the disposal of the exhausted packings is problematic. Another important method is absorption in aqueous alkanolamine solutions which also has its disadvantages, e.g. it can be corrosive, the regeneration has a high energy demand, it can produce hazardous by-products, and except for certain adsorbents it is non-selective. Selectivity is important to avoid unnecessary energy and chemicals consumption. Other methods of gas cleaning that should be mentioned include direct conversion to sulfur, physical or chemical absorption methods and membrane technology [2-3].

The technique based on competitive chemisorption has been known for 60 years now. Certain conditions have to be ensured during the operation for selective and efficient gas purification. The essence of this method is that the contact time has to be very short (below $1 \mathrm{~s}$ ) and the contact has to be very intensive. It cannot be realized with chemisorbers of classical construction. Depending on pressure, $\mathrm{H}_{2} \mathrm{~S}$ is absorbed orders of magnitude faster than $\mathrm{CO}_{2}$ at the beginning of the absorption. The reaction
${ }^{1}$ Institute of Chemical and Process Engineering,

Department of Chemical Engineering Science,

University of Pannonia, H-8200 Veszprém, Hungary

*Corresponding author, e-mail: molnare@almos.uni-pannon.hu 
is strongly $\mathrm{pH}$ dependent [1]. The process converts $\mathrm{H}_{2} \mathrm{~S}$ to $\mathrm{NaHS}$ and $\mathrm{Na}_{2} \mathrm{~S}$, and $\mathrm{CO}_{2}$ to $\mathrm{Na}_{2} \mathrm{CO}_{3}$ [2].

Gas purification by alkaline chemisorptions has already been implemented in reactors with static mixers, countercurrent packed absorbers or countercurrent spray scrubber as well [4-10]. Application of a Jet reactor seems to be an ideal solution. We can solve the spraying of $\mathrm{NaOH}$ solution by the gas to be treated thus the reaction surface can be increased greatly [1].

The liquid and gas phases get mixed due to the generated free turbulent jet if the flow and geometric conditions are ensured. Rapid phase separation is necessary after intensive mixing and can solved with a classical separator. The Jet reactor allows changing a number of parameters. Due to the spraying operation and the design of the reactor measurements the following factors can be changed: pressure, gas and alkali flow rate, $\mathrm{NaOH}$ concentration, diameter of nozzle, gas phase and liquid meeting place, the size and geometry of the reactor, residence time, gas composition [11].

The schematic representation of the spray nozzle is given in the Fig. 1.

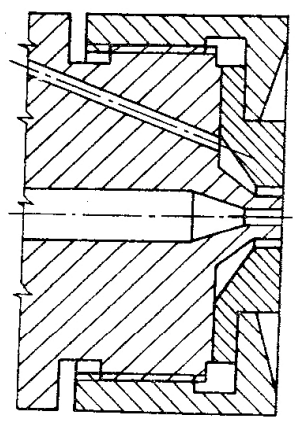

Fig. 1 External mixed pneumatic liquid atomizer [12]

As already mentioned, the free turbulent jet plays an important role in the intensive contact. We can experiment that jets are created, if the fluid flows through a narrow vent with sufficiently high flow rate. The stream of jets can either be laminar or turbulent. If the jet is generated in a relatively large space it is called a free jet. Free jets are characterized by a special flow field, there is a conically narrowing core and the jet sprawls also conically. The jets cause turbulence in confined spaces and tubes thereby the substance of the jet gets mixed with its environment very quickly. For this reason the confusor-diffuser design is often used in the chemical industry. The turbulent free jet is shown in Fig. 2 [13].

The particle size of the droplets and their size distribution are important parameters in the efficiency of the removal. By using the Nukiyama-Tanasawa equation (Eq. (1)) the droplet size can be defined.

$$
D_{s}=\frac{585}{U_{r}}\left(\frac{\sigma}{\rho_{L}}\right)^{0.5}+597\left[\frac{\mu_{L}}{\left(\sigma \rho_{L}\right)^{0.5}}\right]^{0.45}\left(1000 \frac{Q_{L}}{Q_{G}}\right)^{1.5}
$$

where

$\sigma=$ liquid surface tension $\left(\right.$ dyne $\left.\cdot \mathrm{cm}^{-1}\right)$

$\rho_{\mathrm{L}}=$ liquid density $\left(\mathrm{g} \cdot \mathrm{cm}^{-3}\right)$

$\mu_{\mathrm{L}}=$ liquid viscosity (poise)

$\mathrm{Q}_{\mathrm{L}}=$ liquid volume flow rate $\left(\mathrm{cm}^{3} \cdot \mathrm{s}^{-1}\right)$

$\mathrm{Q}_{\mathrm{G}}=$ gas volume flow rate $\left(\mathrm{cm}^{3} \cdot \mathrm{s}^{-1}\right)$

$\mathrm{U}_{\mathrm{r}}=$ relative velocity between liquid and gas $\left(\mathrm{cm} \mathrm{s}^{-1}\right)$ [15].

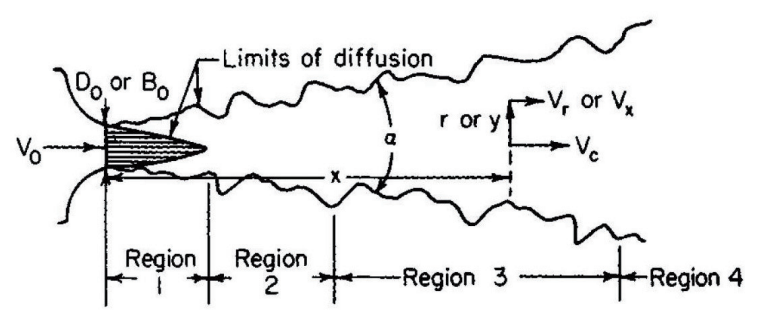

Fig. 2 Free turbulent jet [14]

\section{Experiments}

Pre-experiments were carried out in a batch filled with Raschig rings absorber. Gas mixtures of $\mathrm{H}_{2} \mathrm{~S}$ (120-140 ppm), $\mathrm{CO}_{2}(25-75 \mathrm{v} / \mathrm{v} \%)$ and nitrogen were used for the experiments. $0.5-6.0 \mathrm{~m} / \mathrm{m} \% \mathrm{NaOH}$ solutions were applied as the absorbent. The same effect was observed during each experiment, depicted in Fig. 3.

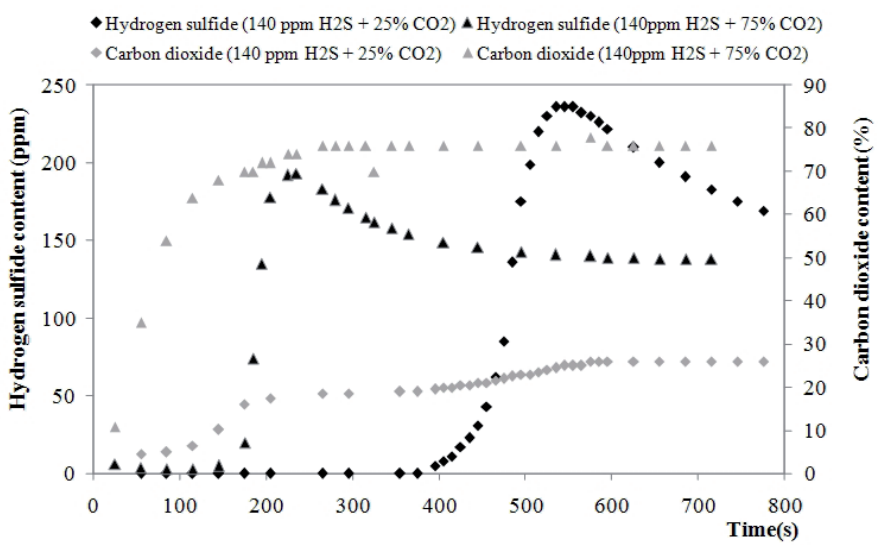

Fig. 3 Illustration of competitive chemisorption in $370 \mathrm{~cm}^{3} 1 \mathrm{~m} / \mathrm{m} \% \mathrm{NaOH}$ absorbent with $150 \mathrm{dm}^{3} \mathrm{~h}^{-1}$ gas volumetric velocity in a packed absorber

Figure 3 shows that the absorption of $\mathrm{H}_{2} \mathrm{~S}$ was $100 \%$ at the beginning, after which the content of $\mathrm{H}_{2} \mathrm{~S}$ increased on the output side. The concentration of $\mathrm{H}_{2} \mathrm{~S}$ on the output side exceeds the original $\mathrm{H}_{2} \mathrm{~S}$ content in the gas mixture. After this the $\mathrm{H}_{2} \mathrm{~S}$ concentration reaches its peak and it decreases back to its original level in the output gas. Shortly after this peak the $\mathrm{CO}_{2}$ concentration also reaches its original level in the output gas. It is also evident from the figure that a higher $\mathrm{CO}_{2}$ content accelerates the saturation of the absorber. Based on the experience, it can be said that $\mathrm{CO}_{2}$ is able to displace the already bound $\mathrm{H}_{2} \mathrm{~S}$ from the absorbent. The two compounds are in a competitive reaction. 
We want to avoid this effect by using a Jet reactor. The use of a Jet reactor provides the opportunity to achieve a continuous operation and to minimize the residence time.

Measurements in a Jet reactor were carried out to examine the correlation of the efficiency and alkaline specificity while changing the size of nozzle, the concentration and the mass flow of $\mathrm{NaOH}$ solution.

The effect of four different size of nozzle was examined. The measurement conditions were as follows: gas volumetric velocity $350-360 \mathrm{Nm}^{3} \cdot \mathrm{h}^{-1}$, alkaline feed $62-124 \mathrm{~kg} \cdot \mathrm{h}^{-1}, \mathrm{NaOH}$ concentration $2.3-2.8 \mathrm{~m} / \mathrm{m} \%$. The reduction of the nozzle size improves efficiency as shown in Fig. 4 , where $D_{1}>D_{2}>D_{3}>D_{4}$. (Based on the results there is no clear correlation regarding base-specificity.)

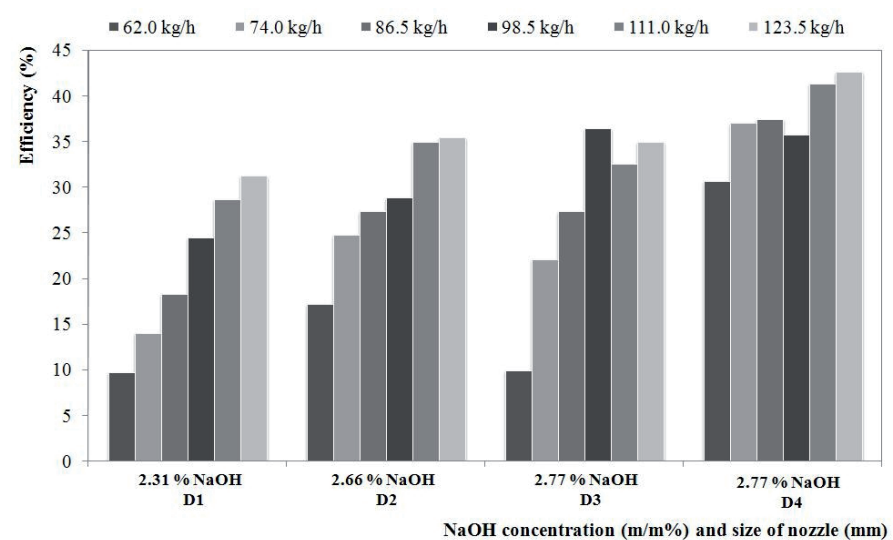

Fig. 4 Effect of alkali concentration and the size of the nozzle for cleaning efficiency of $\mathrm{H}_{2} \mathrm{~S}$ removal

During the examination of correlation of the efficiency, the alkali specificity (ratio of $\mathrm{NaOH}$ and $\mathrm{H}_{2} \mathrm{~S}$ expressed in moles) and the $\mathrm{NaOH}$ flow, the measured alkali interval was between $1.5-3.5 \mathrm{~m} / \mathrm{m} \%$. The input of the $\mathrm{NaOH}$ flow was ensured with a double-headed pump. The mass flow of alkali was changed between $88-189 \mathrm{~kg} \cdot \mathrm{h}^{-1}$, which considering the number of revolutions of the pump corresponds to the interval of 1050-2400 s-1. Meanwhile the volumetric flow of the natural gas was between 230-300 $\mathrm{Nm}^{3} \cdot \mathrm{h}^{-1}$ and its pressure was 3.2-4.2 bar. The size of the nozzle during these measurements was $\mathrm{D}_{4}$. The diameter of the droplets was between 30 and $300 \mathrm{~mm}$ during all tests.

The results show that it is necessary to use high amounts of the alkali to reach a relatively high efficiency, namely high concentration of $\mathrm{NaOH}$ with a high mass flow. Nevertheless, the rate of efficiency improvement is not linear with the concentration of $\mathrm{NaOH}$ or the number of revolutions of the pump as it can be seen in Figs. 5 and 6 .

Considering the range of $\mathrm{NaOH}$ concentration the effect of increasing the mass flow on the efficiency of purification is higher when more dilute alkali solutions are applied. Furthermore, beside low concentration of $\mathrm{NaOH}$ the growth of alkali consumption is relatively smaller when the number of revolutions is increased in the given range. It appears that the middle part of the examined range is the optimal in which the $\mathrm{NaOH}$ concentration is $2-2.5 \mathrm{~m} / \mathrm{m} \%$ and the revolutions of the pump is $1350-18001 \cdot \mathrm{s}^{-1}$. The alkali consumption in this range is below $10 \mathrm{~mol} \mathrm{NaOH} / \mathrm{mol} \mathrm{H}_{2} \mathrm{~S}$ while the efficiency reaches the minimal value of $50 \%$.

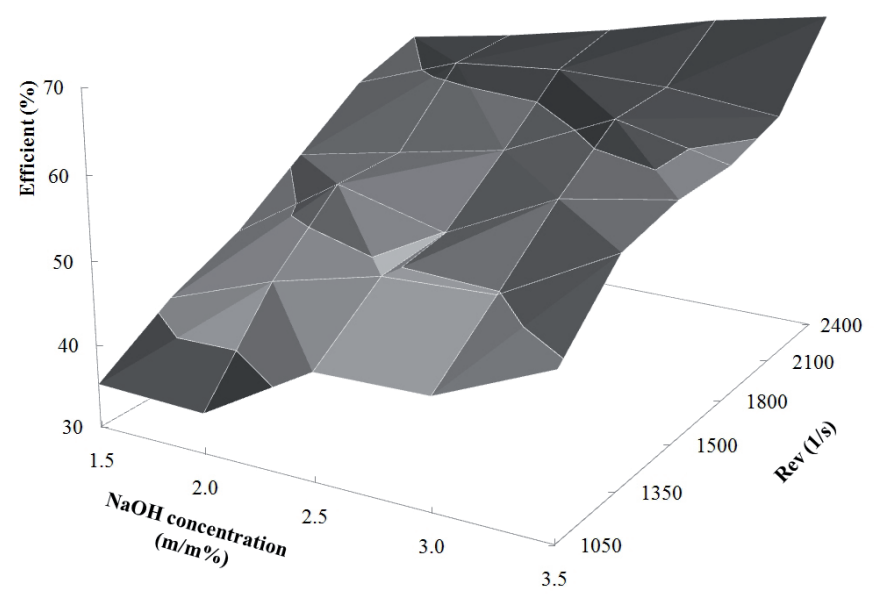

Fig. 5 The change of efficiency depending on the number of revolutions of the pump

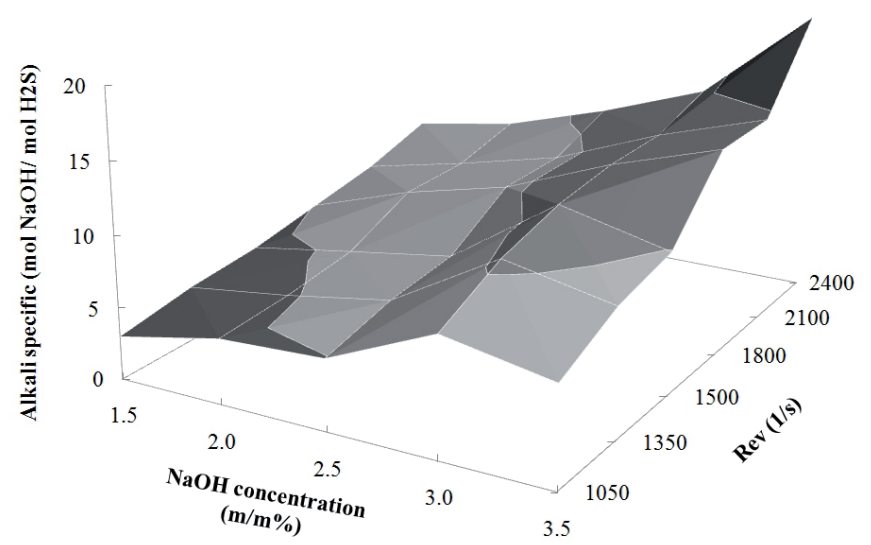

Fig. 6 The change of alkali specific in rev of pump

\section{Conclusions}

Based on the experimental data it can be stated that the residence time can be minimized (0.01-0.04 s) by using a Jet reactor. This enables a continuous operation, where the effect of displacement can be avoided. Using a Jet reactor is effective and the gas cleaning is specific if the appropriate conditions are created. An ideal interval was found in the examined range, where the base concentration is $2-2.5 \mathrm{~m} / \mathrm{m} \%$ and the number of revolutions per second is between 1350 and $1800 \mathrm{~s}^{-1}$. Moreover, considering the impact of the nozzle, we experienced that the reduction of the diameter can achieve significant improvement in the efficiency. 


\section{References}

[1] Vágó, Á., Rippel-Pethő, D., Horváth, G., Tóth, I., Oláh, K. "Removal of $\mathrm{H}_{2} \mathrm{~S}$ from natural gas, a motor vehicle fuel." Hungarian Journal of Industrial Chemistry. 39(2), pp. 283-287. 2011.

[2] Kohl, A. L., Nilsen, R. B. Gas Purification. Houston: Gulf Publishing Company. pp. 1-35 and 402-404. 1997.

[3] Duissenov, D. "Production and processing of sour crude and natural gas - challenges due to increasing stringent regulations." Norwegian University of Science and Technology. Department of Petroleum Engineering and Applied Geophysics. pp. 60-69. 2013.

[4] Üresin, E., Sarac, H. I., Sarioglan, A., Ay, S., Akgün, F. "An experimental study for $\mathrm{H}_{2} \mathrm{~S}$ and $\mathrm{CO}_{2}$ removal via caustic scrubbing system." Process Safety and Environmental Protection. 94, pp. 196-202. 2015. DOI: 10.1016/j.psep.2014.06.013

[5] Panza, D., Belgiorno, V. "Hydrogen sulphide removal from landfill gas." Process Safety and Environmental Protection. 88, pp. 420-424. 2010. DOI: 10.1016/j.psep.2010.07.003

[6] Krischan, J., Makaruk, A., Harasek, M. "Design and scale-up of an oxidative scrubbing process for selective removal of $\mathrm{H}_{2} \mathrm{~S}$ from biogas." Journal of Hazardous Materials. 215-216, pp. 49-56. 2012. DOI: 10.1016/j.jhazmat.2012.02.028

[7] Srinivasan, V., Aiken, R. C. "Selective Absorption of $\mathrm{H}_{2} \mathrm{~S}$ from $\mathrm{CO}_{2}$ Factors Controlling Selectivity toward $\mathrm{H}_{2} \mathrm{~S}$." Fuel Processing Technology. 19(2), pp. 141-152. 1988. DOI: 10.1016/0378-3820(88)90062-8
[8] Hsieh, K. T., Aiken, R. C. "Selective gas absorption under pressure." Chemical Engineering Communications. 31(1-6), pp. 367-382. 1984. DOI: 10.1080/00986448408911160

[9] Turpin, A., Couvert, A., Laplanche, A., Paillier, A. "Experimental study of mass transfer and $\mathrm{H}_{2} \mathrm{~S}$ removal efficiency in a spray tower." Chemical Engineering and Processing. 47, pp. 886-892. 2008.

DOI: $10.1016 /$ j.cep.2007.02.002

[10] Álvarez-Cruz, R., Sánchez-Florez, B. E., Torres-González, J., AntanoLopez, R., Castaneda, F. "Insights in the devepopment of a new method to treat $\mathrm{H}_{2} \mathrm{~S}$ and $\mathrm{CO}_{2}$ from sour gas by alkali." Fuel. 100, pp. 173-176. 2012. DOI: 10.1016/j.fuel.2012.05.009

[11] Bandyopadhyay, A., Biswas, M. N. "CO capture in a spray column using a critical flow atomizer." Separation and Purification Technology. 94, pp. 104-114. 2012. DOI: 10.1016/j.seppur.2011.11.039

[12] Turba, J. "Porlasztók." (Atomizers.) Budapest: Müszaki Könyvkiadó. p. 290. 1976. (in Hungarian)

[13] Szolcsányi, P. "Transzportfolyamatok." (Transport Processes.) Budapest: Tankönyvkiadó. pp. 101-103. 1972. (in Hungarian)

[14] Perry, R. H., Green, D. W., Maloney, J. O. "Perry's Chemical Handbook." McGraw-Hill. p. 563. 1997.

[15] Kashani, A. "Aerosol Characterization and Analytical Modeling of Concentric Pneumatic and Flow Focusing Nebulizers for Sample Introduction." Mechanical and Industrial Engineering Department University of Toronto. p. 28. 2010. 